\title{
A picture or a thousand words: Routine timed barium esophagram after myotomy
}

Jules Lin, MD

From the Department of Surgery, Section of Thoracic Surgery, University of Michigan Medical Center, Ann Arbor, Mich.

Disclosures: Author has nothing to disclose with regard to commercial support.

Received for publication April 3, 2018; accepted for publication April 6, 2018; available ahead of print May 10, 2018 .

Address for reprints: Jules Lin, MD, Section of Thoracic Surgery, 1500 E. Medical Center Drive, 2120TC/5344, Ann Arbor, MI (E-mail: juleslin@umich.edu).

J Thorac Cardiovasc Surg 2018;156:878-9

$0022-5223 / \$ 36.00$

Copyright (c) 2018 by The American Association for Thoracic Surgery

https://doi.org/10.1016/j.jtcvs.2018.04.021

In this issue of the Journal, Kachala and colleagues ${ }^{1}$ describe the potential value of routine timed barium esophagram (TBE) after myotomy for achalasia and found that height and width measurements were associated with outcomes and the need for reintervention. Others have reported similar findings, including a $40 \%$ risk of failure with a $<50 \%$ improvement in height at 1 minute, ${ }^{2,3}$ and Rohof and colleagues ${ }^{4}$ also proposed using TBE instead of manometry to decide on reintervention. A picture is worth a thousand words.

The authors recommend considering reintervention with worsening symptoms or worsening TBE. Does this mean that reintervention should be considered even in the absence of symptoms? They hypothesize that quantifying emptying objectively would be more reliable. Although symptoms do not always correlate with esophageal emptying, ${ }^{5}$ the presence of persistent or recurrent symptoms remains important in considering the balance between the risks and benefits of reintervention. Symptom improvement (decrease in the Eckardt score to less than 3) is also an important factor in determining success. ${ }^{6}$ The authors did not present data on patient symptoms and whether symptoms improved after initial treatment and reintervention. Does improvement in TBE correlate with improvement in symptoms?

With growing use of the Chicago classification, it is becoming increasingly recognized that achalasia is not one homogeneous disorder and that outcomes after intervention depend on the specific type (I-III) of achalasia. ${ }^{7}$ Although the authors have previously described the correlation of TBE with different achalasia subtypes, ${ }^{8}$ they do not describe in the current study how to interpret their TBE findings within these achalasia subgroups and whether the measurements associated with success or risk of reintervention need to be adjusted based on the specific subtype.

As the authors point out, many factors affect esophageal emptying, including the degree of esophageal dilatation and sigmoidal shape. However, most interventions for achalasia focus on palliating incomplete relaxation of the lower

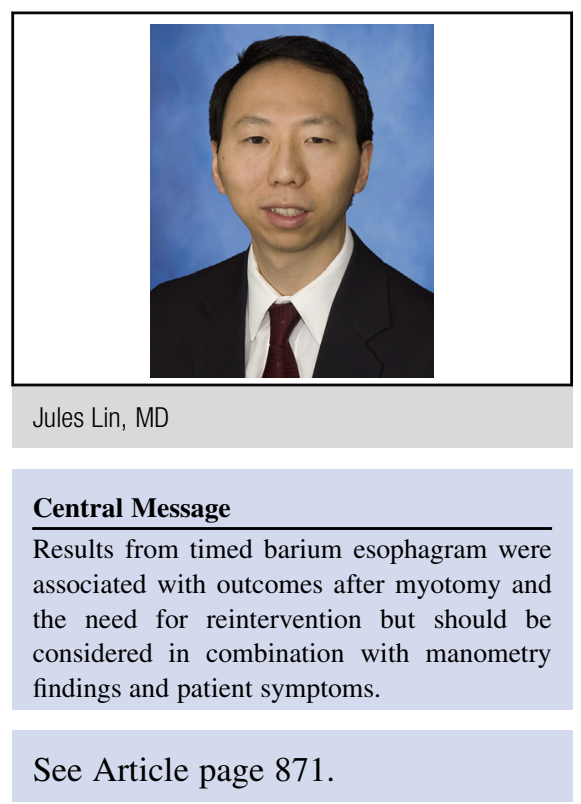

esophageal sphincter. Would it be better to use studies focusing on the lower esophageal sphincter, such as high-resolution manometry or EndoFLIP (endoluminal functional lumen imaging probe)? Although TBE may serve as a screening study for ineffective esophageal emptying, it is important to confirm incomplete relaxation of the lower esophageal sphincter before considering surgical reintervention.

Although the authors have demonstrated the potential value of routine follow-up TBE, one limitation of the study is that TBE was used in clinical decision-making in determining whether patients underwent reintervention, a primary outcome of the study. Further studies are needed to delineate how TBE should be used within each achalasia subtype to optimize patient selection and to evaluate outcomes after peroral endoscopic myotomy. ${ }^{9}$ Is routine follow-up TBE better than simply getting a high-resolution manometry in symptomatic patients? Will treating asymptomatic patients with a high likelihood of recurrent symptoms help prevent progression to end-stage achalasia and avoid the need for esophagectomy? Until more data are available, it remains important to consider both the picture (TBE) and the thousand words (patient symptoms) along with manometry results in selecting patients for reintervention. 


\section{References}

1. Kachala SS, Rice TW, Baker ME, Rajeswaran J, Thota PN, Murthy SC, et al. Value of routine timed barium esophagram follow-up in achalasia after myotomy. $J$ Thorac Cardiovasc Surg. 2018;156:871-7.e2.

2. Andersson M, Lundell L, Kostic S, Ruth M, Lönroth H, Kjellin A, et al. Evaluation of the response to treatment in patients with idiopathic achalasia by the timed barium esophagogram: results from a randomized clinical trial. Dis Esophagus. 2009;22:264-73.

3. Oezcelik A, Hagen JA, Halls JM, Leers JM, Abate E, Ayazi S, et al. An improved method of assessing esophageal emptying using the timed barium study following surgical myotomy for achalasia. J Gastrointest Surg. 2009;13:14-8.

4. Rohof WO, Lei A, Boeckxstaens GE. Esophageal stasis on a timed barium esophagogram predicts recurrent symptoms in patients with long-standing achalasia. Am J Gastroenterol. 2013;108:49-55.
5. Vaezi MF, Baker ME, Achkar E, Richter JE. Timed barium oesophagram: better predictor of long term success after pneumatic dilation in achalasia than symptom assessment. Gut. 2002;50:765-70.

6. Eckardt VF, Aignherr C, Bernhard G. Predictors of outcome in patients with achalasia treated by pneumatic dilation. Gastroenterology. 1992;103: 1732-8.

7. Pandolfino JE, Gawron AJ. Achalasia: a systematic review. JAMA. 2015;313: 1841-52.

8. Zanoni A, Rice TW, Lopez R, Birgisson S, Shay SS, Thota PN, et al Timed barium esophagram in achalasia types. Dis Esophagus. 2015;28: 336-44.

9. Inoue H, Minami H, Kobayashi Y, Sato Y, Kaga M, Suzuki M, et al. Peroral endoscopic myotomy (POEM) for esophageal achalasia. Endoscopy. 2010;42: 265-71. 